\title{
The impact of body mass index on blood pressure measured with a mercury sphygmomanometer in children and adolescents with type 1 diabetes mellitus
}

Liuba M. Aguirre-Salas ${ }^{1}$, J. Jesús Pérez-Molina ${ }^{2,3 *}$, Salvador Fonseca-Reyes ${ }^{4}$, Jorge A. Becerra-Villa ${ }^{2}$ Mayra del C. Silva-Camarena ${ }^{1}$

${ }^{1}$ Servicio de Endocrinología, División de Pediatría, Nuevo Hospital Civil de Guadalajara Dr. Juan I. Menchaca; ${ }^{2}$ División de Pediatría, Nuevo Hospital Civil de Guadalajara Dr. Juan I. Menchaca; ${ }^{3}$ Departamento de Clínicas de la Reproducción Humana, Crecimiento y Desarrollo Infantil, Centro Universitario de Ciencias de la Salud, Universidad de Guadalajara; ${ }^{4}$ Instituto de Investigación Cardiovascular, Centro Universitario de Cienciās de la Salud, Universidad de Guadalajara. Guadalajara, Jalisco, Mexico

\begin{abstract}
Background: Patients with type 1 diabetes mellitus (T1DM) and overweight have more risk to develop changes in bitood pressure that increase cardiovascular morbidity and mortality. In this study, the relationship between blood pressure (BP) cwith the body mass index (BMI) and the average of the last three measurements of glycated hemoglobin (HbA1C) in patients with T1DM was determined. Methods: $A$ cross-sectional analytical study was conducted in children and adolescents with TiDM with over a year since diagnosis. The dependent variables were systolic and diastolic BP, measured with a mercury sphygmomanometer. The independent variables were BMI and average of the last three measurements of HbA1. A Finear regression with a 95\% confidence interval was used. Results: Seventy-five patients with T1DM were studied. The median of disease duration was 3.5 years (min 1-max 14.8 years), BMI $19.5 \pm 3.1 \mathrm{~kg} / \mathrm{cm}^{2}$ and $\mathrm{HbA1c} 8.3 \pm 2.4 \%$. Sixty-six patients showed $B P<$ percentile 90 and $9 B P \geq$ percentile $90(12 \%)$. Two models of linear regression were constructed, with systolic and diastolic $B P$ as dependent variables. The possible predictor variables were suggested by theoretical context and statistical analysis. The predictive variable of high BP was zBMI (body mass index expressed in z-score) for systolic and diastolic BP. Also, the models suggested that for an increase of one unit of $Z B M I$, corresponded a rise of 5.1 and $3.6 \mathrm{mmHg}$ in systolic and diastolic BP, respectively. Conclusions: A positive correlation between systolic and diastolic BP with zBMI was observed.
\end{abstract}

Key words: Type 1 diabetes mellitus. Blood pressure. Body mass index. Glycated hemoglobin. Children. Adolescents

Impacto del índice de masa corporal en la presión arterial medida con esfigmomanómetro de mercurio en niños y adolescentes con diabetes mellitus tipo $\mathfrak{d}$

\section{Resumen}

Introducción: Los pacientes con diabetes mellitus tipo 1 (DM1) y sobrepeso tienen más riesgo de desarrollar cambiós en la presión arterial (PA), y esto incrementa su morbilidad y mortalidad cardiovascular. En este estudio se determinó la reląión entre la PA y el índice de masa corporal (IMC) y el promedio de las tres últimas mediciones de hemoglobina glucosilada

Correspondence:

*J. Jesús Pérez-Molina

E-mail: jesusperezmolina@gmail.com

2444-3409/๑ 2019. Hospital Infantil de México Federico Gómez, published by Permanyer México SA de CV, all rights reserved.
Date of reception: 13-11-2018

Date of acceptance: 25-02-2019

DOI: 10.24875/BMHIME.M19000064
Available online: 14-01-2020 Bol Med Hosp Infant Mex. 2019;76:1192 126 www.bmhim.com 
(HbA1c) de pacientes con DM1. Métodos: Estudio transversal analítico en niños y adolescentes con DM1 con más de un año de evolución. Las variables dependientes fueron la PA sistólica y diastólica medidas con esfigmomanómetro ỹlas variables independientes, IMC y promedio de las últimas tres mediciones de la HbA1C. Se utilizó regresión lineal múltiple con intervalo de confianza del 95\%. Resultados: Se estudiaron 75 pacientes con DM1. La mediana del tiempo de evolucición de la DM1 fue de 3.5 años (mínimo 1 año-máximo 14.8 años), el IMC $19.5 \pm 3.1 \mathrm{~kg} / \mathrm{cm}^{2}$ y la HbA1c $8.3 \pm 2.4 \%$. De los 75 pacientes, 66 presentaron $P A<$ percentil 90 y 9 PA $\geq$ percentil 90 (12\%). Se construyeron dos modelos de regresión lineal múltiple, con PA sistólica y diastólica como variables dependientes. Las posibles variables predictoras fueron sugeridaS por el contexto teórico y el análisis estadístico. EI IMC expresado en puntuación zeta (zIMC) fue predictor para PA sistólica/diastólica. Los modelos sugirieron que a cada incremento de unidad del zIMC corresponde un aumento de 5.1 y $3.6 \mathrm{mmHg}$ de् $P A$ sistólica y diastólica, respectivamente. Conclusiones: Se observó una correlación positiva de la PA sistólica y la diastổlica con el zIMC.

Palabras clave: Diabetes mellitus tipo 1. Presión arterial. Índice de masa corporal. Hemoglobina glucosilada. Niñinos. Adolescentes.

\section{Introduction}

Patients with type 1 diabetes mellitus (T1DM) develop chronic complications that significantly increase their cardiovascular morbidity and mortality: two of the most frequent are hypertension (HTN) and chronic kidney disease. ${ }^{1,2}$

Because of the two-fold risk of HT on children and adolescents, especially with a long time of progression of $\mathrm{T}_{1 \mathrm{DM}}{ }^{3}$, blood pressure (BP) measurement with a strict technique is a mandatory procedure in the evaluation of this metabolic alteration.

In the pediatric clinical environment, and more frequently in the field of research, automated BP measurement has replaced the traditional measurement with the auscultatory method using mercury sphygmomanometer, mainly due to problems of mercury toxicity and increased availability of electronic devices that require less training to use. However, in general, BP readings obtained with electronic devices are significantly higher than those recorded by the auscultatory method, with the risk of overestimating the HTN diagnosis. ${ }^{4}$ Also, it should be noted that the reference values to consider high BP in children and adolescents were initially obtained using the auscultatory method with a mercury sphygmomanometer. ${ }^{5}$

In the different studies in which the relationship between T1DM and high BP has been investigated, 2,3,5 electronic or aneroid devices have been used more frequently, whereas mercury sphygmomanometers have been used occasionally. ${ }^{4,6}$

The association between HTA and T1DM has been explained, in large part, by the higher degree of adiposity and poor metabolic control of the individuals. ${ }^{2-9}$ This association can be influenced by local factors and by the BP measurement technique, for which the objective of this study was to determine the relationship between $\mathrm{BP}$ with body mass index (BMI) and the mean of the last three measurements of glycosylated hemoglobin $(\mathrm{HbA1c})$ in pediatric patients with T1DM.

\section{Methods}

\section{Study population}

An analytical cross-sectional study ${ }^{10}$ was condueted in children and adolescents with T1DM of the Pediatric Endocrinology Service, Nuevo Hospital Civil de Guadalajara Dr. Juan I. Menchaca, from November 2014 to February 2016. The Ethics and Research Committees of the institution approved this research, and written consent was obtained from the parents or tutors.

Diabetic patients with a minimum of one year of disease progression were consecutively included and divided into two groups, one with $\mathrm{BP}<$ percentile 90 and one with $\mathrm{BP} \geq 90$ percentile. ${ }^{11}$ Individuals who presented an $\mathrm{HbA} 1 \mathrm{c}$ value $>7.5 \%$ were considered as "exposed". A sample with $0.05 \%$ alpha error, $20 \%$ beta error, a ratio of 1 between subjects with normotension and hypertension was calculated: $44 \%$ of subjects with T1DM, $\mathrm{HTN}$ and $\mathrm{HbA} 1 \mathrm{c}>7.5 \%, 15 \%$ of subjects with T1DM1, no HTN and $\mathrm{HbA1c} \geq 7.5 \%$. The prevalence of exposure (HbA1C $\geq 7.5$ in 15 and $44 \%$ ) was obtained from patients with T1DM treated in the Endocrinology department of the institution. The minimum odds ratio (OR) detected was 4.4. The suggested sample size was 76 subjects.

Patients with genetic diseases, secondary hypertension, active treatment with drugs that modify BP, $;$ with smoking habit and who used illicit drugs, in addition to patients with incomplete data or those who requested their withdrawal from the study were not included in the study. 


\section{Variables}

The dependent variables were systolic BP (SBP) and diastolic BP (DBP), expressed in $\mathrm{mmHg}$ for age, sex, and height, in addition to the diagnosis of normotension and prehypertension. ${ }^{11}$

The independent variables were metabolic control, determined by the mean of the last three $\mathrm{HbA1c}$ values, and adiposity, measured through the BMI.

T1DM was considered when two or more fasting blood glucose determinations were $\geq 126 \mathrm{mg} / \mathrm{dl}$ or random blood glucose $\geq 200 \mathrm{mg} / \mathrm{dl}$ with symptoms of hyperglycemia, and values of $\mathrm{HbA1c} \geq 6.5 \%$ were detected..$^{12}$ Also, the presence of an abrupt clinical picture of ketosis and the absence of acanthosis nigricans were considered as clinical evidence of insulin resistance.

Metabolic control was defined as the mean of the last three $\mathrm{HbA1c}$ determinations, measured within four months. The values $\leq 7.5 \%$ were considered as adequate glycemic control and $>7.5 \%$ as poor glycemic control for statistical analysis.

BMI was used as an indirect measure of the degree of adiposity, according to the World Health Organization (WHO), which is classified as low ( $\leq 1$ standard deviation [SD]); normal ( $\pm 1 \mathrm{SD}$ ); overweight (from $>1 \mathrm{SD}$ to $\leq 2 \mathrm{SD}$ ) and obesity (> $2 \mathrm{SD}) .^{13}$

\section{Procedures}

The informed consent and assent were obtained after explaining the investigation to the tutors and patients. Patients with T1DM who met the inclusion criteria attended to a direct interview for data collection and the determination of anthropometric parameters using the Habicht method. ${ }^{13}$

Individuals were evaluated in the hypertension clinic by an observer explicitly trained in the correct technique of BP measurement, according to the criteria estab-

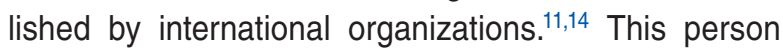
measured the BP of the individuals three times in each of the two visits, with an interval of two to six weeks between both appointments. The BP was measured between 10:00 $\mathrm{h}$ and 13:00 $\mathrm{h}$ with a non-foldable desktop mercurial sphygmomanometer (Tycos ${ }^{\circledR}$ Instrument, North Carolina, USA). The procedure was explained to each child, and they were told not to speak during the measurement. The patients remained seated, with their back supported and their feet placed on a flat surface, in a comfortable environment, and at rest for five minutes. The arm was uncovered to the shoulder and supported on a horizontal surface at the level of the heart. Previously, the arm circumference was measured to meet the requirement of using the most appropriate arm cuff, with a width of $40 \%$ and a length of $80-100 \%$. The arm cuff was centered on the brachial artery, without excessively tightening it, or leaving it too loose; the lower edge was $3 \mathrm{~cm}$ above the antecubital fossa. Subsequently, the maximum inflation level was determined by the Osler maneuver, which consists of palpating the radial artery and concomitantly inflating the arm cuff $30 \mathrm{mmHg}$ above the point of disappearance ofthe pulse corresponding to the SBP, to avoid pain ordiscomfort during measurement. The cuff was deflated the stethoscope was placed over the brachial artery with the entire surface in contact with the skin, the arm cuff was quickly and steadily inflated to the predetermined level, releasing the air from the chamber at a speed of $2 \mathrm{mmHg}$ per heartbeat. The cuff was not re-inflated after having started deflation to confirm SBP or DBP. SBP was determined when two continuous beats appeared (Korotkoff phase I) and DBP at the moment where the noises disappeared (Korotkoff phase V). An additional $10 \mathrm{mmHg}$ after the last noise was examined to confirm the disappearance of the noises.

\section{Statistical analysis}

The mean and standard deviation of the quantitative variables were calculated. In the case of a normal distribution, the means were compared with the Student's t-test for two independent variables. Whenothe distribution was asymmetric, the median was determined and compared using the Mann-Whitney U Test. Qualitative variables were expressed in proportions and compared using the $\chi^{2}$ or Fisher's exact tests. The association of qualitative variables with the BP $\geq 90$ percentile was determined with OR.

A multiple linear regression analysis was performed to study the relationship between SBP and DBP $\underline{\text { with }}$ $\mathrm{BMI}$, the mean of the last three $\mathrm{HbA1c}$ measurements, and the time of progression. In all calculations, the confidence interval was $95 \%(95 \% \mathrm{Cl})$. The analyses were performed with the statistical program for sócial sciences (SPSS Statistics for Macintosh, Version 22.0. Armonk, NY: IBM Corp.).

\section{Results}

Seventy-five children and adolescents with T1DM, with an average age of $14.3 \pm 2$ years (range of 10 to 19 years), $56 \%$ males and a male/female ratio of $1: 3$ were studied. The average weight was $48.2 \pm 12.3 \mathrm{~kg}$ (range 25.6 
Table 1. Characteristics of individuals with type 1 diabetes mellitus with $B P \geq P 90$ and with $B P<P 90$

\begin{tabular}{|c|c|c|c|c|c|}
\hline \multirow[t]{2}{*}{ Variable } & \multicolumn{2}{|c|}{$\mathrm{BP} \geq \mathrm{P90}(\mathrm{n}=9)$} & \multicolumn{2}{|c|}{$B P<P 90(n=66)$} & \multirow[t]{2}{*}{$\boldsymbol{p}^{*}$} \\
\hline & Mean & SD & Mean & SD & \\
\hline Age (years) & 14.3 & 1.9 & 14.3 & 2.1 & 0.9 \\
\hline Birth weight (g) & 3077 & 493 & 3183 & 672 & 0.65 \\
\hline Weight $(\mathrm{kg})^{* *}$ & 58.6 & $34-88$ & 50.1 & $25-80$ & 0.45 \\
\hline BMI $\left(\mathrm{kg} / \mathrm{m}^{2}\right)$ & 22.3 & 2.9 & 19.7 & 3.1 & 0.0 \\
\hline Waist circumference $(\mathrm{cm})$ & 74.8 & 8.1 & 68.7 & 6.6 & 0.01 \\
\hline Time of progression (years) ${ }^{* *}$ & 7.2 & $1-12$ & 3.4 & $1-15$ & 0.45 \\
\hline Total insulin dose per day (IU) & 56.0 & 17.7 & 48.2 & 18.5 & \\
\hline Insulin dose per kg of weight per day (IU) & 1.0 & 0.3 & 0.9 & 0.3 & 0.57 \\
\hline HbA1c (\%) & 9.7 & 2.3 & 8.7 & 2.4 & 0.26 \\
\hline $\mathrm{SBP}(\mathrm{mmHg})$ & 112.7 & 11.9 & 102.5 & 8.4 & 0.00 \\
\hline $\mathrm{DBP}(\mathrm{mmHg})$ & 75.6 & 9.9 & 67.9 & 6.1 & 0.00 \\
\hline
\end{tabular}

to $87.7 \mathrm{~kg}$ ), and the BMI was $19.5 \pm 3.1 \mathrm{~kg} / \mathrm{m}^{2}$ : low weight in $13.3 \%$, normal weight in $68 \%$, and overweight in $18.6 \%$. No obesity was detected in any case. The progression of T1DM was $4.6 \pm 3.6$ years, with a median of 3.5 years, a minimum of 1 and a maximum of 14.8 years. The progression period of T1DM was $<5$ years in $66.7 \%$ and $\geq 5$ in $33.3 \%$ of the cases.

The total insulin dose per day was $49 \pm 18 \mathrm{IU}$. HbA1C was determined in 74 patients, with an average percentage of $8.3 \pm 2.4 \%$ : HbA1c was $<6.5$ in $12.2 \%$; 6.5 to $<8$ in $32.4 \%$; $\geq 8$ to $<10$ in $29.7 \%$; $\geq 10$ to $<12$ in $13.5 \%$, and $\geq 12$ in $12.2 \%$.

The last three $\mathrm{HbA} 1 \mathrm{c}$ measurements mean was $>7.5 \%$ in seven individuals with $\mathrm{BP} \geq 90$ percentile $(78 \%)$ and in 41 subjects with $\mathrm{BP}<$ percentile $90(62 \%)$.

The frequency of the quantitative variables was normal, given that the values of the typical error of the asymmetry index and kurtosis index were close to 0.5 and $<1$, respectively.

SBP and DBP levels were $103.7 \pm 9.4 \mathrm{mmHg}$ and $68.8 \pm 7 \mathrm{mmHg}$, respectively. Sixty-six individuals showed $\mathrm{BP}<$ percentile 90 and nine $\mathrm{BP} \geq$ percentile 90 (12\%). Of these, high SBP was observed in $4 \%$, high DBP in $6.6 \%$, and both SBP and DBP in $1.3 \%$.

When comparing the quantitative variables of patients with $\mathrm{BP} \geq$ percentile 90 and with normal BP, the averages for age, birth weight, current weight, progression time, total insulin dose, and $\mathrm{HbA} 1 \mathrm{c}$ were similar in both study groups. Moreover, the mean BMI and waistcircumference were higher in the group of patients with $\mathrm{BP} \geq$ percentile 90 (Table 1).

From the comparison of the qualitative variables, it was found that the family history of HTN and obesity, being preterm at birth, weight gain $>15 \mathrm{~kg}$ of the mother during pregnancy, percentage of progression $\geq$ 5 years and $\mathrm{HbA} 1 \mathrm{c}>7.5 \%$ were distributed simifarly in both study groups.

Moreover, female gender and higher BMI and waist ratio were more frequent in patients with prehyperfension (Table 2).

Two multiple linear regression models were consteucted to analyze the correlation between quantitative variables and BP, with SBP and DBP as dependent variables. The possible predictor variables were those that the theoretical context and the previous statistical analysis suggested. After checking the ANOVA summary with a significant linear relationship $(p<0.001)$ and the independent residues with each other (Durbin-Watson statistic of 1.94 for SBP and 2.1 for DBP and mean of residuals of zero), the only predictor variable of $\mathrm{BP} \geq$ percentile 90 was the BMI for both SBP $(\beta=0.54 ; p$ $<0.001)$ and DBP $(\beta=0.51 ; p<0.001)$.

Regression models also suggested a $5.1 \mathrm{mmHg}$ increase in SBP (Table 3) and $3.02 \mathrm{mmHg}$ DBP (Table 4) for each increment of a zBMI unit (BMI expressed in zeta scores). 
Table 2. Medical history of individuals with type 1 diabetes mellitus with $\mathrm{BP} \geq \mathrm{P} 90$ and with $\mathrm{BP}<\mathrm{P} 90$

\begin{tabular}{|c|c|c|c|c|c|c|}
\hline \multirow[t]{2}{*}{ Variable } & \multicolumn{2}{|c|}{$\mathrm{BP} \geq \mathrm{P} 90$} & \multicolumn{2}{|c|}{$\mathrm{BP}<\mathrm{P} 90$} & \multirow[t]{2}{*}{ OR (95\%CI) } & \multirow[t]{2}{*}{$p^{*}$} \\
\hline & $n / N$ & $\%$ & $\mathrm{n} / \mathrm{N}$ & $\%$ & & \\
\hline Female gender & $7 / 9$ & 77.7 & $26 / 66$ & 39.9 & $5.4(1.1-27.9)$ & 0.037 \\
\hline Family history of hypertension & $5 / 9$ & 55.5 & $35 / 66$ & 53.1 & $1.1(0.3-4.5)$ & 0.443 \\
\hline Family history of obesity & $6 / 9$ & 66.6 & $42 / 66$ & 63.6 & $1.1(0.3-4.9)$ & 0.586 \\
\hline Being preterm at birth & $1 / 9$ & 11.1 & $8 / 66$ & 12.1 & $0.9(0.1-8.2)$ & 0.705 \\
\hline Weight gain $>15 \mathrm{~kg}$ during pregnancy & $2 / 9$ & 22.2 & $21 / 64^{* *}$ & 32.8 & $0.6(0.1-3.1)$ & 0.267 \\
\hline Clinical progression of T1DM > 3.5 years & $6 / 9$ & 66.6 & $31 / 66$ & 46.9 & $2.2(0.5-9.8)$ & 0.453 \\
\hline Overweight due to high adiposity & $4 / 9$ & 44.4 & $10 / 66$ & 15.1 & $4.5(1.0-19.6)$ & 0.017 \\
\hline Waist ratio ( $\geq 0.5$ vs. $<0.5$ ) & $2 / 9$ & 22.2 & $4 / 66$ & 6.1 & $4.4(0.7-28.7)$ & $0.04 \underline{\underline{6}}$ \\
\hline $\mathrm{HbA} 1 \mathrm{c}>7.5 \%$ (average of the last three measurements) & $7 / 9$ & 78.0 & $41 / 66$ & 62.0 & $2.1(0.4-11.1)$ & 0.600 \\
\hline \multicolumn{6}{|c|}{$\begin{array}{l}\text { *p-value when comparing the proportions with the } x^{2} \text { test or Fisher's exact test. } \\
\text { **Information from some individuals was not available. } \\
\text { BP, blood pressure; P90, percentile } 90 ; 0 R \text {, odds ratio; } 95 \% \mathrm{Cl}, 95 \% \text { confidence interval; T1DM, type } 1 \text { diabetes mellitus; HbA1c, glycosylated hemoglobin. }\end{array}$} & 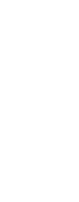 \\
\hline
\end{tabular}

\begin{tabular}{|c|c|c|c|c|c|}
\hline \multicolumn{6}{|c|}{ Systolic blood pressure as a dependent variable } \\
\hline \multirow[t]{2}{*}{ Predictor variables } & \multicolumn{2}{|c|}{ Non-standardized coefficients } & \multirow{2}{*}{$\frac{\text { Typified coefficients }}{\text { Beta }}$} & \multirow[t]{2}{*}{$95 \%$ CI } & \multirow[t]{2}{*}{$p$} \\
\hline & B & Typical error & & & \\
\hline Constant & 103.262 & 3.183 & & $96.91-109.61$ & $<0.000$ \\
\hline zBMI & 5.086 & 1.037 & 0.538 & $3.02-7.15$ & $<0.00 \underline{-1}$ \\
\hline Female gender & 1.631 & 1.980 & -0.86 & $-5.58-2.31$ & 0.413 \\
\hline Progression time & 3.389 & 2,098 & -0.180 & $-7.57-0.797$ & 0.11 立 \\
\hline $\mathrm{HbA1c}$ & -2.268 & 2.042 & -0.116 & $-6.34-1.80$ & 0.270 \\
\hline Insulin dose per kg of weight & 4.573 & 3.019 & 0.169 & $-1.45-10.60$ & 0.1340 \\
\hline
\end{tabular}

ANOVA of the model. Significance $\leq 0.001$; adjusted $R^{2}=0.218$. Diabetes mellitus progression time $>3.5$ years. Each increase in a $z$ BMI unit corresponds to an increase of $5.086 \mathrm{mmHg}$ of systolic blood pressure.

$\mathrm{HbA1c}$, the average of the last three measurements of glycosylated hemoglobin; $\mathrm{Cl}$, confidence interval; zBMI, body mass index expressed as zeta score.

\section{Discussion}

Children and adolescents have an increased risk of vascular and renal complications during the evolution of T1DM. ${ }^{8}$ Gröber-Grätz et al. found a higher prevalence of other risk factors, such as overweight and obesity, which may be associated with increased cardiovascular morbidity in children with no diabetes. ${ }^{15}$ Flores-Huerta et al. also documented a positive association of overweight and obesity with BP levels (obtained with different measurement techniques) in children and adolescents with no diabetes, in whom a higher BMI correlated with higher systolic and diastolic BP. ${ }^{16}$ However, none of these studies performed a correlation analysis between BMI with SBP and DBP. Furthermore, higher association and prediction of cardiovascular damage has been demonstrated with the method known as 24hour Ambulatory BP Monitoring (ABPM) compared to the measurement in the medical office. ${ }^{17}$

Children and adolescents with diabetes and a bigh degree of adiposity, apart from their frequent lack of glycemic control, have a significant risk of presenting higher BP levels and, consequently, a greater cardiovascular risk. ${ }^{18}$ Although some studies have addressed this relationship in different ethnic populations of diabetic children worldwide, ${ }^{2,3,17}$ the effect of increased adiposity on the BP level in the mestizo Mexican population or other Latin American populations is unknown. $\frac{t}{\sigma}$

In this study, BMI was used as an indirect measure to estimate the degree of adiposity, since it wwas 
Table 4. Multiple linear regression with diastolic blood pressure as a dependent variable

\begin{tabular}{|c|c|c|c|c|c|}
\hline \multicolumn{6}{|c|}{ Diastolic blood pressure as a dependent variable } \\
\hline \multirow[t]{2}{*}{ Predictor variables } & \multicolumn{2}{|c|}{ Non-standardized coefficients } & \multirow{2}{*}{$\frac{\text { Typified coefficients }}{\text { Beta }}$} & \multirow[t]{2}{*}{$95 \%$ CI } & \multirow[t]{2}{*}{$\boldsymbol{p}$} \\
\hline & B & Typical error & & & \\
\hline Constant & 68.381 & 2.391 & & $63.61-73.15$ & $<0.001$ \\
\hline zBMI & 3.597 & 0.779 & 0.511 & $2.04-5.15$ & $<0.001$ \\
\hline Female gender & -0.854 & 1.487 & -0.061 & $-3.82-2.1$ & 0.568 \\
\hline Progression time & 0.170 & 1.576 & 0.012 & $-2.97-3.31$ & $0.9 \overline{14}$ \\
\hline $\mathrm{HbA1c}$ & -0.356 & 1.534 & -0.024 & $-3.42-2.70$ & 0.817 \\
\hline Insulin dose per kg of weight & 1.041 & 2.268 & 0.052 & $-3.48-5.56$ & $0.6 \overline{48}$ \\
\hline
\end{tabular}

ANOVA of the model. Significance $\leq 0.001$; adjusted $R^{2}=0.204$. Diabetes mellitus progression time $>3.5$ years. Each increase in a $z B M I$ unit corresponds to an increase of $3.6 \mathrm{mmHg}$ of diastolic blood pressure.

$\mathrm{HbA1c}$, the average of the last three measurements of glycosylated hemoglobin; $\mathrm{Cl}$, confidence interval; zBMI, body mass index expressed as zeta score.

reported to be a useful marker of body fat. The relationship between BMI and BP was also studied. ${ }^{19}$ The results obtained showed a relationship between $\mathrm{BMI}$ and SBP $(\beta=0.54)$ and $\operatorname{DBP}(\beta=0.51)$. It was also found that each increase of a $\mathrm{zBMl}$ score unit in children with diabetes corresponded to a $5.1 \mathrm{mmHg}$ increase in SBP and $3.6 \mathrm{mmHg}$ in DBP. After evaluating 164 patients with T1DM in Poland, whose BP was measured with an electronic device, Pietrzak et al. also found a correlation between BMI and SBP $(\beta=0.37)$ and DBP $(\beta=0.28){ }^{3}$

Other authors, such as Guimaraes et al. ${ }^{6}$ in Brazil, who measured BP with a mercury device and a strict measurement technique in a large sample of 536 non-diabetic children and adolescents, and Van Vliet et $\mathrm{al}^{8}$. in the Netherlands, who measure it in 283 children with T1DM, found a frequency of high SBP and DBP in subjects with high BMI. Unfortunately, no correlation analysis was performed in either of these studies. In the latter study, nearly $40 \%$ of subjects presented overweight or obesity and a higher prehypertension frequency. In contrast, in a small sample of 60 adolescents with T1DM whose BP was measured in the medical office with a validated electronic device, de Oliveira et al. ${ }^{2}$, in Brazil, found no significant correlation between the increase in BMI and BP; however, a statistical trend was observed between overweight and a higher DBP.

In the present work, $12 \%$ of individuals were found with $\mathrm{BP} \geq$ percentile 90 , but none with $\mathrm{BP} \geq$ percentile 95 most likely because of the small sample size, since Margeirsdottir et al., after studying a population of 1,658 patients with T1DM in Norway, found BP $\geq$ percentile 95 in $4 \%$ of the children and a percentage with
$\mathrm{BP} \geq$ percentile 90 but $\mathrm{BP}<$ percentile $95,{ }^{1}$ similar to the frequency of the present study.

Different biological mechanisms have been identified as an explanation for this relationship between higher BMI and higher BP. For example, with mpore adipose tissue, insulin resistance increases, and more inflammatory cytokines are released, with the consequent rise in oxidative stress. Furthermore the renin-angiotensin-aldosterone system is activated, vascular dysfunction and sodium retention $z$ are increased, and more activity of the sympathetic mervous system is observed in association with increased renal dysfunction, which is usually more intense inthe presence of albuminuria and contributes to increased cardiovascular risk. ${ }^{20}$

Another variable that has been associated with a higher level of BP in children with T1DM is poor glycemic control. In this sense, de Oliveira et al..$^{2}$ observed that children and adolescents with significant uncontrolled glycemia $(11.6 \% \mathrm{HbA} 1 \mathrm{c})$ showed higher levels of systolic and diastolic BP. Also, they found a positive correlation with diastolic $\mathrm{BP}$, showing an increase of $1.73 \mathrm{mmHg}$ for every $1 \%$ increase in $\mathrm{HbA} 1 \mathrm{c}$.

In a retrospective study, Torchinsky et al. ${ }^{21}$ evaluăted 148 children with T1DM in the US and found a higher average level of DBP and heart rate with higher $\mathrm{HBA} 1 \mathrm{C}$ levels. Moreover, a correlation with insulin doses was even observed. In another study, in which BP was measured in 106 North American children with T1DM ussing ABPM with bivariate analysis, Chatterjee et al. ${ }^{7}$ also found a higher frequency of lack of glycemic control in subjects with prehypertension and hypertension. In contrast, no positive correlation between $\mathrm{HbA} 1 \mathrm{c}$ and $\mathrm{BP}-$ by linear regression was demonstrated by Pietrzak etzal. ${ }^{3}$ 
In this study, no correlation was found between glycemic control and BP, although there was a higher frequency of elevated $\mathrm{HbA1c}$ in subjects with prehypertension in the bivariate analysis. However, it was not statistically significant. It should be noted that the average $\mathrm{HbA1c}$ levels in this study were similar to those reported by other authors. ${ }^{3,7}$

Regarding the time of progression of T1DM, a relationship with BP was not observed. However, Pietrzak et al. ${ }^{3}$ documented a positive correlation between the time of progression and the DBP. Also, de Oliveira et al. ${ }^{2}$ reported a higher frequency of prehypertension with a longer time of progression of the T1DM1, only in the bivariate analysis.

It is worth mentioning that individuals with $\mathrm{BP} \geq$ percentile 90 showed a longer time of disease progression, higher HbA1c levels, and a higher proportion of inadequate glycemic control. However, despite being clinically significant values, they showed no statistical significance. Similarly, weight gain $>15 \mathrm{~kg}$ during pregnancy was not relevant.

A limitation of the present study was the small sample size, since with a prevalence of $12 \%$ of $B P \geq$ percentile 90 , assuming the prevalence of exposure to $\mathrm{HbA1C}$ of $15 \%$ and $44 \%$, the power of the study is close to $60 \%$ to identify an OR of 4.5 . However, in this investigation, the OR of exposure to $\mathrm{HbA} 1 \mathrm{c}$ of $15 \%$ and $44 \%$ was close to 2 and the power to $20 \%$. Regardless, the sample size was satisfactory to test the relationship between BMI and BP. Another limitation would be that adiposity was estimated through the BMI and not with other forms of evaluation. Regarding the above, WHO suggests that adiposity can be estimated with the BMI since there is an adequate correlation between them. ${ }^{13}$

In summary, a positive correlation was found between systolic and diastolic BP and the $\mathrm{zBMI}$ in this study, which was similar to that reported in other studies of children with T1DM. No correlation was found between $\mathrm{BP}$ with the mean of the last three $\mathrm{HbA1C}$ measurements, probably due to the small sample size.

Therefore, it is essential to achieve a balance between income and energy expenditure in clinical practice through an adequate diet, physical activity, and satisfactory use of insulin to avoid exaggerated adiposity gain. Also, the monitoring and screening of macrovascular and microvascular complications is essential in patients with T1DM, according to the ISPAD 2018 guidelines. ${ }^{22}$

\section{Ethical disclosures}

Protection of human and animal subjects. JThe authors declare that no experiments were performed on humans or animals for this study.

Confidentiality of data. The authors declare that they have followed the protocols of their work center on the publication of patient data.

Right to privacy and informed consent. The authors have obtained the written informed consent of the patients or subjects mentioned in the article. Fhe corresponding author is in possession of this document.

\section{Conflicts of interest}

The authors declare that they have no conflicts of interest.

\section{Funding}

None.

\section{References}

1. Margeirsdottir HD, Larsen JR, Brunborg C, Overby NC, Dahl-Jørgensen K, Norwegian Study Group for Childhood Diabetes. High prevalence of cardiovascular risk factors in children and adolescents with type 1 diabetes: a population-based study. Diabetotogia. 2008;51:554-61.

2. De Oliveira S, da Cunha Nascimento D, Tibana RA, de Oliveira SE, de Sousa Neto IV, Falleiros Maciel RK, et al. Elevated glycated hemoglobin levels impair blood pressure in children and adolescents with type 1 diabetes mellitus. Diabetol Metab Syndr. 2016;8:4.

3. Pietrzak I, Mianowska B, Gadzicka A, Młynarski W, Szadkowska A. Blood pressure in children and adolescents with type 1 diabetes mellitus-the influence of body mass index and fat mass. Pediatr Endocrinol Diabetes Metab. 2009;15:240-5.

4. Fonseca-Reyes S, Romero-Velarde E, Torres-Gudiño E, Illescas-Zárate D, Forsyth-MacQuarrie AM. Comparison of auscultatory and oscillometric BP measurements in children with obesity and their effect on the diagnosis of arterial hypertension. Arch Cardiol Mex. 2018; 88:16-24.

5. Rohani F, Hooman N, Moradi S, Mobarra M, Najafizadeh M, Tatarpoor P. The prevalence of pre-hypertension in children with type 1 diabetes mellitus. Int J Prev Med. 2014:5:S44-9.

6. Guimarães IC, de Almeida AM, Santos AS, Barbosa DB, Guimarães AC. Blood pressure: effect of body mass index and waist circumference on adolescents. Arq Bras Cardiol. 2008;90:393-9.

7. Chatterjee M, Speiser PW, Pellizzarri M, Carey DE, Fort P, Kreitzer PM, et al. Poor glycemic control is associated with abnormal changes in 24hour ambulatory blood pressure in children and adolescents with type 1 diabetes mellitus. J Pediatr Endocrinol Metab. 2009;22:1061-7.

8. Van Vliet M, Van der Heyden JC, Diamant M, Von Rosenstiel IA, Schindhelm RK, Aanstoot HJ, et al. Overweight is highly prevalent in children with type 1 diabetes and associates with cardiometabolic risk. J Pediatr. 2010;156:923-9

9. Knerr I, Dost A, Lepler R, Raile K, Schober E, Rascher W, et al. 'Diabetes Data Acquisition System for Prospective Surveillance (DPV) Scientific Initiative Germany and Austria. Tracking and prediction of apterial blood pressure from childhood to young adulthood in 868 patients with type 1 diabetes: a multicenter longitudinal survey in Germany and Austria. Diabetes Care. 2008;31:726-7.

10. Hernández B, Velasco-Mondragón HE. Encuestas transversales. Salud Publica Mex. 2000;42:447-55.

11. National High Blood Pressure Education Program Working Groüp on High Blood Pressure in Children and Adolescents. The fourth report on the diagnosis, evaluation, and treatment of high blood pressure iD children and adolescents. Pediatrics. 2004;114:555-76. 
12. Casallas Osorio JA. La Guía Completa y Actualizada para el diagnóstico, tratamiento y prevención de las complicaciones de la Diabetes Mellitus. ADA (American Diabetes Association); 2013. Available from: https://www. intramed.net/userfiles/2013/file/diabetes_2013.pdf.

13. World Health Organization. Measuring change in nutritional status Guidelines for assessing of nutritional impact of supplementary feeding programs for vulnerable groups. Geneva: WHO; 1983.

14. Lurbe E, Cifkova R, Cruickshank JK, Dillon MJ, Ferreira I, Invitti C, European Society of Hypertension, et al. Management of high blood pressure in children and adolescents: recommendations of the European Society of Hypertension. J Hypertens. 2009;27:1719-42.

15. Gröber-Grätz D, Widhalm K, de Zwaan M, Reinehr T, Blüher S, Schwab KO, et al. Body mass index or waist circumference: which is the better predictor for hypertension and dyslipidemia in overweight/obese children and adolescents? Association of cardiovascular risk related to body mass index or waist circumference. Horm Res Paediatr. 2013;80:170-8.

16. Flores-Huerta $S$, Klünder-Klünder $M$, Reyes de la Cruz L, Santos JI. Increase in body mass index and waist circumference is associated with high blood pressure in children and adolescents in Mexico City. Arch Med Res. 2009;40:208-15.
17. Kotsis V, Stabouli S, Bouldin M, Low A, Toumanidis S, Zakopoutos N. Impact of obesity on 24-hour ambulatory blood pressure and hypertension. Hypertension. 2005;45:602-7.

18. Díaz-Cárdenas $C$, Wong $C$, Vargas-Catalán NA. Grado de controlmetabólico en niños y adolescentes con diabetes mellitus tipo 1. Rev Chil Pediatr. 2016;87:43-7.

19. Romero-Velarde E, Vásquez-Garibay EM, Álvarez-Román YA, Fonseca-Reyes S, Casillas-Toral E, Troyo-Sanromán R. Circunfereneia de cintura y su asociación con factores de riesgo cardiovascular en niños y adolescentes con obesidad. Bol Med Hosp Infant Mex. 2013;70:358-63.

20. Cheung BM, Li C. Diabetes and hypertension: is there a common metabolic pathway? Curr Atheroscler Rep. 2012;14:160-6.

21. Torchinsky MY, Gomez R, Rao J, Vargas A, Mercante DE, Chalew SA. Poor glycemic control is associated with increased diastolic blood tpressure and heart rate in children with type 1 diabetes. J Diabetes Complications. 2004;18:220-3.

22. Donaghue KC, Marcovecchio ML, Wadwa RP, et al. ISPAD Clinical Practice Consensus Guidelines 2018: Microvascular and macrovascular complications in children and adolescents. Pediatr Diabetes. 2018;19:262-74. 